

\title{
In vivo modulation of a dominant-negative variant in mouse models of von Willebrand disease type $2 \mathrm{~A}$
} \author{
Matteo Campioni, Paulette Legendre, Cécile Loubiere, Barbara Lunghi, Mirko
}

Pinotti, Olivier D Christophe, Peter J. Lenting, Cécile Denis, Francesco Bernardi, Caterina Casari

\section{To cite this version:}

Matteo Campioni, Paulette Legendre, Cécile Loubiere, Barbara Lunghi, Mirko Pinotti, et al.. In vivo modulation of a dominant-negative variant in mouse models of von Willebrand disease type $2 \mathrm{~A}$. Journal of Thrombosis and Haemostasis, 2020, Online ahead of print. 10.1111/jth.15131 . inserm-02983110

\section{HAL Id: inserm-02983110 https://www.hal.inserm.fr/inserm-02983110}

Submitted on 29 Oct 2020

HAL is a multi-disciplinary open access archive for the deposit and dissemination of scientific research documents, whether they are published or not. The documents may come from teaching and research institutions in France or abroad, or from public or private research centers.
L'archive ouverte pluridisciplinaire HAL, est destinée au dépôt et à la diffusion de documents scientifiques de niveau recherche, publiés ou non, émanant des établissements d'enseignement et de recherche français ou étrangers, des laboratoires publics ou privés. 
In vivo modulation of a dominant-negative variant in mouse models of von Willebrand disease type $2 \mathrm{~A}$

Matteo Campioni ${ }^{1 *}$, Paulette Legendre ${ }^{2^{*}}$, Cécile Loubiere ${ }^{2}$, Barbara Lunghi ${ }^{1}$, Mirko Pinotti ${ }^{1}$, Olivier D Christophe ${ }^{2}$, Peter J Lenting ${ }^{2}$, Cécile V Denis ${ }^{2}$, Francesco Bernardi ${ }^{1}$ and Caterina Casari $^{2}$

1Department of Life Science and Biotechnology, University of Ferrara, 44124 Ferrara, Italy ${ }^{2}$ Institut National de la Santé et de la Recherche Médicale, Unité Mixte de Recherche Scientifique 1176, Université Paris-Sud, Université Paris-Saclay, 94276 Le Kremlin-Bicêtre, France

${ }^{*}$ M.Campioni and P.Legendre contributed equally to this work

Running title: Modulating dominant-negative variants in VWD mice

Correspondence: Caterina Casari, INSERM U1176, 80 rue du General Leclerc, 94276 Le Kremlin-Bicêtre, France Tel: +33149595615; Fax: +33146719472;

Email: caterina.casari@inserm.fr

Word count:

Abstract: 241

Main text: 2082

Figures: 3

References: 29 


\section{Essentials:}

- Treatment options for von Willebrand disease (VWD) patients are limited.

- The p.P1127_C1948delinsR deletion/variant is a useful model to study VWD in vitro and in vivo.

- Counteracting dominant-negative effects restores von Willebrand factor multimerization in mice.

- First siRNA-based treatment applied to a mouse model of VWD-type 2A.

\section{Abstract}

Background: Treatment options for patients suffering from von Willebrand disease (VWD) are limited. Willebrand factor (VWF) is a polymeric protein that undergoes regulated dimerization and subsequent multimerization during its biosynthesis. Numerous heterozygous variants within the VWF-gene display a dominant-negative effect and result in severe von Willebrand disease (VWD). Previous studies have suggested that preventing the assembly of wild-type and mutant heteropolymers using siRNAs may have beneficial effects on VWF phenotypes in vitro.

Objectives: To study heterozygous dominant-negative variants in vivo, we developed a mouse model of VWD-type $2 A$ and tested two independent strategies to modulate its detrimental effect.

Methods: The p.P1127_C1948delinsR deletion/variant, causing defective VWF multimerization was expressed in mice as a model of VWD-type 2A variant. Two corrective strategies were applied. For the first time in a mouse model of VWD, we applied siRNAs selectively inhibiting translation of the mutant transcripts and we combined the VWD-type $2 A$ deletion with the Cys to Arg substitution at position 2773, which is known to prevent dimerization.

Results: The RNA silencing approach induced a modest but consistent improvement of the VWF multimer profile. However, due to incomplete efficiency, the dominant-negative effect of the original variant could not be completely prevented. In contrast, the DNA-approach resulted in increased antigen levels and restoration of a normal multimer profile.

Conclusions: Our data showed that preventing the detrimental impact of dominant-negative VWF variants by independent molecular mechanisms has beneficial consequences in vivo, in mouse models of dominant VWD.

Keywords: von Willebrand factor, von Willebrand disease, in vivo RNA interference, mouse models, dominant-negative variants. 


\section{Introduction.}

In contrast to the recent therapeutic advances in haemophilia $A / B$ or Thrombotic Thrombocytopenic Purpura, treatment options for patients with von Willebrand disease (VWD) have remained essentially unchanged for decades. While plasma-derived drugs have been available since the 80 s, the FDA approved the use of recombinant von Willebrand factor (VWF), in 2015. However, this did not revolutionize the therapeutic strategy for VWD, which essentially consists of supplementing VWF to restore platelet adhesion and aggregation[1]. Hundreds of genetic alterations have been identified in the VWF gene accounting for a highly heterogeneous disease with complicated diagnostic and treatment options. Many heterozygous variants display dominant-negative effects due to the multimeric nature of the protein[2-4]. Best known are heterozygous changes in the carboxy- and amino-terminal end of VWF, which impair dimerization[5-7] or multimerization[8-11], respectively, and lead to termination of the growing process when a mutant-subunit is incorporated into a polymer. In the attempt to explore a new therapeutic approach for VWD, we previously demonstrated that counteracting the dominant-negative effect of heterozygous pathogenic variants, applying siRNAs selectively targeting the altered allele, prevents the assembly of wild-type and mutant heteropolymers and has beneficial effect in cellular models of VWD[12]. Although further confirmed in vitro by others[13], the value of this approach has not yet been demonstrated in vivo.

Despite important research efforts (reviewed in [14-16]), efficient in vivo targeted delivery to endothelial cells or megakaryocytes has not been achieved yet and represents a major obstacle that hampers the use of silencing- or gene editing-based therapies, for example using the CRISPR-Cas9 system, in VWD animal models and VWD patients.

To study heterozygous dominant-negative variants in vivo, we developed a mouse model of VWD-type 2A, the p.P1127_C1948delinsR deletion/variant[12], causing defective VWF multimerization, and tested two independent strategies to modulate its detrimental effect: i) for the first time in a mouse model of VWD, we applied siRNAs selectively inhibiting translation of the mutant transcripts and demonstrated a moderate improvement in VWF multimer profile or ii) we combined the VWD-type 2A deletion with the Cys to Arg substitution at position 2773, a variant known to prevent VWF dimerization[5, 7], and observed both an increase in antigen levels and restoration of a normal multimer profile.

Our data showed that preventing the detrimental impact of dominant-negative VWF variants by independent molecular mechanisms has beneficial consequences in mouse models of dominant VWD.

\section{Materials \& Methods:}

Animals \& ethics statement. 
Vwf-deficient mice[17] are housed in our animal facility and have been backcrossed greater than 10 generations onto the $\mathrm{C} 57 \mathrm{BL} / 6 \mathrm{~J}$ background. Males and females were used throughout the study (8-12 weeks old, 20-25g). Experiments were performed in accordance with French regulations and guidelines of the European Community. The local ethical committee of Université Paris-Sud (comité d'éthique en experimentation animale n 26) approved this project (number 20037/2019032714308918 v3).

\section{Plasmids for VWF expression in vitro and in vivo}

Plasmid for the expression of murine VWF-WT has been previously described[18, 19]. A DNA fragment mimicking the DEL variant[12], which merges exon 25 and 35 in frame, was synthesized and cloned into the pLIVE-VWF/WT to obtain a pLIVE-VWF/DEL (p.P1127_C1948delinsR) plasmid. Subsequently, a DNA fragment containing the p.C2773R[5, 7] substitution was synthesized and cloned into the pLIVE-VWF/DEL to obtain the double mutant pLIVE-VWF/DEL/C2773R.

$50 \mu \mathrm{g}$ of total DNA or equal amounts of two plasmids $(25 \mu \mathrm{g})$ to mimic heterozygous conditions[20] were injected for in vivo expression of exogenous murine VWF via hydrodynamic gene transfer (HGT)[18, 21, 22].

Plasmid for the expression of human (h)VWF-WT and -DEL have been previously described[12, 23]. A DNA fragment containing the p.C2773R was synthesized and cloned into the pSV-hVWF/DEL to obtain the double mutant pSV-hVWF/DEL/C2773R. In vitro experiments have been conducted as previously described[12]. VWF multimeric composition and antigen levels were evaluated in cellular media collected 72 hours post-transfection.

In vivo study design \& corrective approaches

Heterozygous mouse models of VWD due to a dominant-negative variant were established using the hydrodynamic gene transfer (HGT) in Vwf-deficient mice[17] to express the previously characterized p. P1127_C1948delinsR in frame deletion (DEL)[12], which impairs VWF multimerization, together with wild type VWF (VWF/WT).

Invivofectamine 2.0 or 3.0 was applied for systemic, highly efficient in vivo siRNA delivery to mouse liver[24, 25]. siRNA (siDEL) specific for VWF-DEL silencing were selected based on previous cellular studies[12] and purchased as custom Ambion In Vivo siRNAs (HPLC purified) with high stability and no toxicity. Ambion In Vivo Negative Control (siNEG) with no sequence similarity to mouse gene sequences were used as negative controls. siRNAs were administered accordingly to manufacturer's indications IV at 7 or $1 \mathrm{mg} / \mathrm{kg}$ (for Invivofectamine 2.0 and 3.0, respectively) 4-days post HGT. All reagents used for in vivo silencing were from ThermoFisher Scientific. 
For the DNA-approach, we co-injected by HGT the pLIVE-double mutant plasmid with the pLIVE containing VWF-WT cDNA.

Blood was collected at indicated time points by retro-orbital puncture from isofluraneanesthetized mice, in $10 \% \mathrm{vol} / \mathrm{vol}$ triNa-citrate $(0.138 \mathrm{M})$. Plasma for VWF analysis was prepared by centrifugation for 20 minutes at $1500 \mathrm{xg}$ at room temperature.

\section{VWF assays}

VWF multimer profile was performed essentially as previously described[26] in 2-3\% agarose gels. In mouse plasma, VWF was detected with an in-house Alkaline phosphatase-conjugated polyclonal goat anti-VWF (recognizing both human and mouse VWF) \& colorimetric Alkaline phosphatase-substrate kit (Bio-Rad Laboratories, Hercules, USA). In cellular media, a primary polyclonal rabbit anti-human VWF \& a secondary HRP-conjugated goat anti-rabbit IgG (both from Dako, Glostrup, Denmark) followed by chemiluminescent detection was applied.

VWF antigen levels were measured with an in-house E.L.I.S.A. assay essentially as previously described[27]. For mVWF, a pooled plasma prepared from 20 (males and females) C57BI/6 mice was used as reference. Mice with a maximum antigen level of $1500 \%$ have been included in this study. For hVWF a human pooled normal plasma (Cryopep, Montpellier, France) was used as reference.

\section{Tail-clip bleeding assay}

Four days post-HGT, tail-clip was performed essentially as previously described[19, 21]. Mice expressing VWF antigen levels between 300 and $1500 \%$ have been used for this assay.

\section{Results and Discussion:}

When the VWF-DEL (p.P1127_C1948delinsR)[12] and VWF-WT combination was expressed in Vwf-deficient mice[17] (Figure 1A), plasma multimer analysis revealed that high molecular weight multimers (HMWMs) were absent (Figures 1B and 3B). Every oligomer displayed one extra-band consistent with heteropolymers of lower molecular weight, confirming that both plasmids were expressed by the same hepatocytes, mimicking heterozygous conditions. Indeed, since dimerization and multimerization occur intracellularly, the dominant-negative effect can be detected only under conditions of co-expression within the endoplasmic reticulum. Our results show that heterozygous mice reflect patient phenotype[10, 28, 29]. Hepatocyte-mediated VWF-DEL expression was then inhibited in heterozygous mice expressing both VWF-WT \& VWF-DEL, by infusing siRNAs selectively targeting the new junction between exons 25 and 35 only present in the DEL variant (siDEL, previously referred as si3681 [12]) in complex with the Invivofectamine reagent. The effect of siDEL administration was evaluated first on VWF multimer profiles and as shown on Figure 1B (left panel) higher 
multimer bands were visible after treatment and more consistently, the odd-bands corresponding to heteropolymers were decreased, reflecting selective reduction of VWF-DEL expression. In contrast, in mice receiving negative control siRNAs not targeting any mouse gene product (siNEG), VWF multimers and each WT- and odd-band appeared similar before and after treatment (Figure 1B, right panel). These qualitative observations were further validated by plotting and comparing gel profiles (Figure $1 \mathrm{C}$ ), confirming how siDEL but not siNEG modulated VWF expression. To quantify these observations, we performed a densitometric analysis of the multimer bands and estimated the amount of heteropolymers in each -mer before and after siRNA treatment (Figure 1D). The intensity of the odd band at the dimer, tetramer and hexamer level was significantly decreased after siDEL- but not siNEGtreatment.

VWF antigen was also measured in plasma of mice expressing VWF-WT \& VWF-DEL, three and five days post-HGT, i.e. one day before- and one day after siRNA treatment (Figure 1E). Circulating VWF was essentially stable in siNEG-treated and untreated mice, whereas siDELtreatment, resulted in a $25 \%$ increase in VWF antigen levels $(p=0.004)$. Importantly, this increase was detected in 14 out of 16 siDEL-receiving mice (87.5\%) (Figure 1E, bottom panel). These results show that siRNAs can be successfully targeted to the liver of mice expressing VWF post-HGT and selectively modulate VWF-DEL expression. Nevertheless, full phenotypic correction was not achieved, which can be explained by the fact that siRNA-mediated silencing does not result in complete inhibition of protein expression. Indeed, only 50-80\% of target mRNA knockdown was previously reported using Invivofectamine[25]. Due to the higher translation efficiency and strong dominant-negative effect of the VWF-DEL, it is conceivable that even low amounts of VWF-DEL are then able to terminate multimer polymerization intracellularly thus preventing complete multimer correction and subsequent plasmatic antigen restoration. In addition, some limitations can be ascribed to the mouse model: first, mice subjected to HGT express supraphysiologic levels of the exogenous protein, synthesized almost exclusively by the portion of hepatocytes $(60-70 \%)$ that have internalized the expression plasmids; second, the RNA interfering approach relies on the physical entry of siRNAs into the same hepatocytes, and we could speculate that a proportion of transfected hepatocytes did not internalize the siRNAs, thus contributing to the incomplete phenotypic correction. Many studies are ongoing to find innovative and cell-specific delivery strategies. If successful, endothelial cell targeted-siRNA will represent a great improvement to test silencing-based therapies for VWD directly into genetically engineered mice with physiologic VWF expression rates and for longer period of time, overcoming the limitations and variability due to the HGT model.

We subsequently hypothesized that an alternative genetic approach targeting the altered allele would prevent the dominant-negative effect of the DEL variant. To test this hypothesis, we 
investigated the consequences of combining the in-frame deletion[10, 12, 28, 29] preventing multimerization, with the p.C2773R substitution[5,7], which impairs VWF dimerization. We first conducted experiments in cellular models (Figure 2A) and showed that the inability of the double-variant to interact with wild-type subunits resulted in a significant improvement of VWF multimer profiles (Figure 2B) but had almost no effect on antigen levels, possibly due to a limitation of the cellular model (Figure 2C). Analysis of VWF forms present in the culture medium of cells expressing VWF-WT \& -DEL/C2773 combination showed the selective presence of VWF-WT, suggesting that VWF-DEL/C2773R monomers are retained intracellularly (not shown).

In vivo, heterozygous mice expressing a combination of VWF-WT \& VWF-DEL were compared with heterozygous mice expressing both VWF-WT \& VWF-DEL/C2773R (double-variant) or with homozygous mice expressing VWF-WT only (Figure 3A). While multimer profiles of mice expressing the VWF-WT \& VWF-DEL combination lacked HMWMs and presented extra-bands (arrowheads), multimer profiles of mice receiving both VWF-WT \& the double-variant VWFDEL/C2773R were indistinguishable from that of mice expressing only VWF-WT. This striking restoration of multimers was accompanied by disappearance of the uneven, abnormal bands (Figure 3B). Moreover, antigen levels, which were severely reduced in VWF-WT \& VWF-DEL expressing mice, compared to mice expressing only VWF-WT $(124.2 \pm 122.7 \%$ vs $917.7 \pm 436.4 \%$, respectively), were highly increased in heterozygous mice expressing the double-variant, reaching $70 \%(683.9 \pm 391.6 \%)$ of the levels expressed by control VWF-WT mice (Figure 3C).

To test the hemostatic potential of heterozygous mice expressing the double mutant VWF we performed a tail clip-bleeding assay. VWF:Ag levels $\geq 300 \%$ are necessary to achieve hemostatic efficiency after HGT[18]. In heterozygous mice expressing VWF-WT \& VWF-DEL, only a few approached this threshold and all bled profusely (Figure 3D, red), confirming that the dominant-negative variant is associated with a severe hemorrhagic phenotype (Figure 3E). In contrast, bleeding tendency in mice co-expressing both VWF-WT and VWF-DEL/C2773R was similar to that of control mice, as indicated by the low amount of blood lost by both groups (Figure 3D, black and blue, respectively). Although introducing additional genetic variants to correct the detrimental effects of an inherited pathogenic alteration does not seem clinically feasible, these results indicate that gene-editing approaches inactivating a dominant-negative allele might represent a valuable option that could be applied to VWD in the future.

In summary, here we proved that counteracting the dominant-negative effect of heterozygous gene alterations by applying independent molecular mechanisms has beneficial effects on in vivo models of VWD. More studies are needed to achieve selective targeting of endogenous VWF-expressing cells. Based on our data, we speculate that gene-editing approaches might 
be more powerful to correct dominant-negative variants compared to silencing-based approaches, which -so far- cannot completely suppress production of the mutant subunits, allowing for the DN effect to be reduced but not completely inhibited. Whether silencingapproaches are more powerful in vivo on different genetic variants remains to be investigated. However, this proof-of-concept study demonstrates that innovative, personalized treatment could represent alternative therapeutic options for VWD.

Authorship Contributions M.Campioni, P.Legendre, C.Loubiere. and B.Lunghi performed in vitro experiments and analyzed data, C.Casari performed in vivo experiments and analyzed data, M.Pinotti and O.D.Christophe provided important intellectual input, P.J.Lenting, C.V.Denis, F.Bernardi and C.Casari designed and supervised the study, C.Casari wrote the manuscript and all authors contributed to the editing of the final manuscript.

Disclosure of Conflicts of Interest The authors declare no competing financial interests.

Acknowledgements This study was supported by ITMO-IHP (Instituts Thématiques Multiorganismes Immunologie, Hématologie et Pneumologie) and Fonds de Dotation CSL-Behring (France) (C.Casari) and by an Italian grant Fondo giovani Ricercatori (M.Campioni).

\section{References}

1 Peyvandi F, Kouides P, Turecek PL, Dow E, Berntorp E. Evolution of replacement therapy for von Willebrand disease: From plasma fraction to recombinant von Willebrand factor. Blood Rev. 2019; 38: 100572. 10.1016/j.blre.2019.04.001.

2 Sadler JE, Budde U, Eikenboom JC, Favaloro EJ, Hill FG, Holmberg L, Ingerslev J, Lee CA, Lillicrap D, Mannucci PM, Mazurier C, Meyer D, Nichols WL, Nishino M, Peake IR, Rodeghiero F, Schneppenheim R, Ruggeri ZM, Srivastava A, Montgomery RR, Federici AB, Working Party on von Willebrand Disease C. Update on the pathophysiology and classification of von Willebrand disease: a report of the Subcommittee on von Willebrand Factor. J Thromb Haemost. 2006; 4: 2103-14. 10.1111/j.1538-7836.2006.02146.x.

3 Leebeek FW, Eikenboom JC. Von Willebrand's Disease. N Engl J Med. 2016; 375: 206780. 10.1056/NEJMra1601561.

4 de Jong A, Eikenboom J. Von Willebrand disease mutation spectrum and associated mutation mechanisms. Thromb Res. 2017; 159: 65-75. 10.1016/j.thromres.2017.09.025.

5 Schneppenheim R, Brassard J, Krey S, Budde U, Kunicki TJ, Holmberg L, Ware J, Ruggeri ZM. Defective dimerization of von Willebrand factor subunits due to a Cys-> Arg mutation in type IID von Willebrand disease. Proc Natl Acad Sci U S A. 1996; 93: 3581-6. 10.1073/pnas.93.8.3581.

6 Enayat MS, Guilliatt AM, Surdhar GK, Jenkins PV, Pasi KJ, Toh CH, Williams MD, Hill FG. Aberrant dimerization of von Willebrand factor as the result of mutations in the carboxyterminal region: identification of 3 mutations in members of 3 different families with type $2 \mathrm{~A}$ (phenotype IID) von Willebrand disease. Blood. 2001; 98: 674-80. 10.1182/blood.v98.3.674. 
7 Schneppenheim R, Budde U, Obser T, Brassard J, Mainusch K, Ruggeri ZM, Schneppenheim S, Schwaab R, Oldenburg J. Expression and characterization of von Willebrand factor dimerization defects in different types of von Willebrand disease. Blood. 2001; 97: 2059-66. 10.1182/blood.v97.7.2059.

8 Eikenboom JC, Matsushita T, Reitsma PH, Tuley EA, Castaman G, Briet E, Sadler JE. Dominant type 1 von Willebrand disease caused by mutated cysteine residues in the D3 domain of von Willebrand factor. Blood. 1996; 88: 2433-41.

9 Castaman G, Eikenboom JC, Missiaglia E, Rodeghiero F. Autosomal dominant type 1 von willebrand disease due to G3639T mutation (C1130F) in exon 26 of von Willebrand factor gene: description of five Italian families and evidence for a founder effect. Br J Haematol. 2000; 108: 876-9. 10.1046/j.1365-2141.2000.01944.x.

10 Bodo I, Katsumi A, Tuley EA, Eikenboom JC, Dong Z, Sadler JE. Type 1 von Willebrand disease mutation Cys1149Arg causes intracellular retention and degradation of heterodimers: a possible general mechanism for dominant mutations of oligomeric proteins. Blood. 2001; 98: 2973-9. 10.1182/blood.v98.10.2973.

11 Tjernberg P, Vos HL, Castaman G, Bertina RM, Eikenboom JC. Dimerization and multimerization defects of von Willebrand factor due to mutated cysteine residues. $J$ Thromb Haemost. 2004; 2: 257-65. 10.1111/j.1538-7836.2003.00435.x.

12 Casari C, Pinotti M, Lancellotti S, Adinolfi E, Casonato A, De Cristofaro R, Bernardi F. The dominant-negative von Willebrand factor gene deletion p.P1127_C1948delinsR: molecular mechanism and modulation. Blood. 2010; 116: 5371-6. 10.1182/blood-2010-02268920.

13 de Jong A, Dirven RJ, Oud JA, Tio D, van Vlijmen BJM, Eikenboom J. Correction of a dominant-negative von Willebrand factor multimerization defect by small interfering RNAmediated allele-specific inhibition of mutant von Willebrand factor. J Thromb Haemost. 2018; 16: 1357-68. 10.1111/jth.14140.

14 Kowalski PS, Leus NG, Scherphof GL, Ruiters MH, Kamps JA, Molema G. Targeted siRNA delivery to diseased microvascular endothelial cells: cellular and molecular concepts. IUBMB Life. 2011; 63: 648-58. 10.1002/iub.487.

15 Nabzdyk CS, Pradhan-Nabzdyk L, LoGerfo FW. RNAi therapy to the wall of arteries and veins: anatomical, physiologic, and pharmacological considerations. J Transl Med. 2017; 15: 164. 10.1186/s12967-017-1270-0.

16 Tai W, Gao X. Functional peptides for siRNA delivery. Adv Drug Deliv Rev. 2017; 110111: 157-68. 10.1016/j.addr.2016.08.004.

17 Denis C, Methia N, Frenette PS, Rayburn H, Ullman-Cullere M, Hynes RO, Wagner DD. A mouse model of severe von Willebrand disease: defects in hemostasis and thrombosis. Proc Natl Acad Sci U S A. 1998; 95: 9524-9. 10.1073/pnas.95.16.9524.

18 Marx I, Christophe OD, Lenting PJ, Rupin A, Vallez MO, Verbeuren TJ, Denis CV. Altered thrombus formation in von Willebrand factor-deficient mice expressing von Willebrand factor variants with defective binding to collagen or GPIlbllla. Blood. 2008; 112: 603-9. 10.1182/blood-2008-02-142943.

19 Rayes J, Hollestelle MJ, Legendre P, Marx I, de Groot PG, Christophe OD, Lenting PJ, Denis CV. Mutation and ADAMTS13-dependent modulation of disease severity in a mouse model for von Willebrand disease type 2B. Blood. 2010; 115: 4870-7. 10.1182/blood-2009-11254193.

20 Legendre P, Navarrete AM, Rayes J, Casari C, Boisseau P, Ternisien C, Caron C, Fressinaud E, Goudemand J, Veyradier A, Denis CV, Lenting PJ, Christophe OD. Mutations in 
the $A 3$ domain of von Willebrand factor inducing combined qualitative and quantitative defects in the protein. Blood. 2013; 121: 2135-43. 10.1182/blood-2012-09-456038.

21 Marx I, Lenting PJ, Adler T, Pendu R, Christophe OD, Denis CV. Correction of bleeding symptoms in von Willebrand factor-deficient mice by liver-expressed von Willebrand factor mutants. Arterioscler Thromb Vasc Biol. 2008; 28: 419-24. 10.1161/ATVBAHA.107.159442.

22 Casari C, Du V, Wu YP, Kauskot A, de Groot PG, Christophe OD, Denis CV, de Laat B, Lenting PJ. Accelerated uptake of VWF/platelet complexes in macrophages contributes to VWD type 2B-associated thrombocytopenia. Blood. 2013; 122: 2893-902. 10.1182/blood2013-03-493312.

23 Wagner DD, Saffaripour S, Bonfanti R, Sadler JE, Cramer EM, Chapman B, Mayadas TN. Induction of specific storage organelles by von Willebrand factor propolypeptide. Cell. 1991; 64: 403-13. 10.1016/0092-8674(91)90648-i.

24 Safdar H, Cheung KL, Salvatori D, Versteeg HH, Laghmani el H, Wagenaar GT, Reitsma $\mathrm{PH}$, van Vlijmen BJ. Acute and severe coagulopathy in adult mice following silencing of hepatic antithrombin and protein C production. Blood. 2013; 121: 4413-6. 10.1182/blood-2012-11465674.

25 Eguchi A, De Mollerat Du Jeu X, Johnson CD, Nektaria A, Feldstein AE. Liver Bid suppression for treatment of fibrosis associated with non-alcoholic steatohepatitis. $J$ Hepatol. 2016; 64: 699-707. 10.1016/j.jhep.2015.11.002.

26 Groot E, Fijnheer R, Sebastian SA, de Groot PG, Lenting PJ. The active conformation of von Willebrand factor in patients with thrombotic thrombocytopenic purpura in remission. $J$ Thromb Haemost. 2009; 7: 962-9. 10.1111/j.1538-7836.2009.03433.x.

27 Lenting PJ, Westein E, Terraube V, Ribba AS, Huizinga EG, Meyer D, de Groot PG, Denis CV. An experimental model to study the in vivo survival of von Willebrand factor. Basic aspects and application to the R1205H mutation. I Biol Chem. 2004; 279: 12102-9. 10.1074/jbc.M310436200.

28 Bernardi F, Marchetti G, Guerra S, Casonato A, Gemmati D, Patracchini P, Ballerini G, Conconi $\mathrm{F}$. A de novo and heterozygous gene deletion causing a variant of von Willebrand disease. Blood. 1990; 75: 677-83.

29 Bernardi F, Patracchini P, Gemmati D, Pinotti M, Schwienbacher C, Ballerini G, Marchetti G. In-frame deletion of von Willebrand factor A domains in a dominant type of von Willebrand disease. Hum Mol Genet. 1993; 2: 545-8. 10.1093/hmg/2.5.545.

\section{Figure Legends}

Figure 1. Counteracting the dominant-negative effect of the heterozygous DEL-variant in vivo: silencing approach.

(A) Vwf-deficient mice were subjected to HGT with equal amount $(25 \mu \mathrm{g})$ of two plasmids to coexpress VWF-WT \& VWF-DEL mimicking the heterozygous condition. Four days post-HGT (D4) when protein expression is at maximum level, selected mice received a single intravenous infusion of siRNAs. Blood was collected $24 \mathrm{~h}$ before (D3) and $24 \mathrm{~h}$ after (D5) siRNA-treatment. (B) Representative multimer profiles of mice before (-) and after (+) siDEL- or siNEGadministration. Arrowheads indicate heteropolymers composed of wild-type and lighter mutant subunits. White space between samples indicates different gels. Dotted red lines highlight 
HMWMs visible after siDEL treatment. (C) Representative profile plots for multimers shown in B. Arrowheads indicate lighter heteropolymers. Dotted red lines highlight HMWMs visible after siDEL treatment. Multimer profile plots were obtained using the Gel Analyzer tool of ImageJ (version 2.0.0). (D) Densitometric analysis of multimer profiles. Membranes were imaged with a G:BOX Chemi XT16 Image Systems and densitometric quantification was performed using Gene Tools version 4.0.0.0 (Syngene) software. Quantitative densitometric analysis was performed on samples for which the same amount of VWF, based on VWF:Ag measurement, could be loaded on the same gel in our standard conditions for multimer analysis. As an estimation of the amount of the heteropolymers, the ratio between the intensity of the oddband and the intensity of the total band (WT- \& odd-band intensities) was then calculated for each -MER. Three (siNEG) or four (siDEL) representative mice with sharp multimeric profiles before and after siRNA administration have been quantified. (E, upper panel) VWF antigen levels was measured at D3 \& D5 in mice receiving siDEL ( $n=16$, red), siNEG ( $n=4$, gray) and in control untreated mice ( $n=19$, black). Antigen levels in heterozygous mice at D3 were arbitrary set at $100 \%(97.35 \pm 81.08 \%$ of a reference mouse pooled plasma). (E, bottom panel) Mice were divided between those who raised (grey) or lowered (white) their antigen levels at D5 compared to D3 post-HGT.

Statistical significance was calculated by applying 2-way ANOVA for repeated matched values with Sidak's multiple comparisons test using Prism 7 (Graphpad) software, in D and E. (* $P<0.05 ;{ }^{* *} P<0.01$ and $\left.n s P>0.05\right)$. Error bars in the graphs indicate standard deviation from the mean.

Figure 2. Counteracting the dominant-negative effect of the heterozygous DEL-variant in vitro: DNA targeting approach.

(A) COS-1 cells were transiently transfected with the same total amount of one (pSVhVWF/WT) or two plasmids (pSV-hVWF/WT \& pSV-hVWF/DEL or pSV-hVWF/WT \& pSV-hVWF/DEL/C2773R), in presence of Lipofectamine2000 (Life Technologies Corporation, Carlsbad, USA) essentially as previously described[12]. VWF multimeric composition and antigen levels were evaluated in cellular media collected 72 hours post-transfection.

(B) Representative multimer profile of hVWF transiently expressed in COS-1 cells in high resolution $3 \%$ agarose gels. White space between two lanes indicates non-consecutive samples loaded on the same gel. (C) VWF antigen levels in cells expressing hVWF-WT (black, $n=7$ ), hVWF-WT \& -DEL (red, $n=6$ ) and hVWF-WT \& -DEL/C2773R (blue, $n=7$ ). Antigen levels for hVWF, were calculated using a pooled normal human plasma (Cryocheck, Cryopep, Montpellier, France) as reference. Levels at D3 have been arbitrary set at $100 \%$ for this analysis. Statistical significance was calculated by applying a one-way ANOVA with Tukey's 
multiple comparisons using Prism 7 (Graphpad) software. ( ${ }^{* * *} \mathrm{P}<0.001$ and ns $\mathrm{P}>0.05$ ). Error bars in the graphs indicate standard deviation from the mean.

Figure 3. Counteracting the dominant-negative effect of the heterozygous DEL-variant in vivo: DNA targeting approach.

(A) Vwf-deficient mice were subjected to HGT with one (control mice) or two plasmids (heterozygous VWD models). 4 days after HGT blood was collected and VWF assays performed on mouse plasma. (B) Representative multimer profile of plasmatic VWF in $2 \%$ agarose gels in mice co-expressing VWF-WT \& VWF-DEL, VWF-WT \& VWF-DEL/C2773R and a control mouse expressing VWF-WT only. Arrowheads indicate heteropolymers containing DEL variants. (C) VWF antigen levels in mice expressing VWF-WT $(n=21$, black circles), both VWF-WT \& VWF-DEL ( $n=52$, red circles) and both VWF-WT \& VWFDEL/C2773R ( $n=9$, blue circles). VWF:Ag is expressed as \% of a reference mouse pooled plasma from 10 female and 10 male C57BI/6 mice. (D) A group of mice was subjected to tailclip bleeding assay 4 days after HGT. Blood loss in mice expressing VWF-WT, $n=8$, black circles; both VWF-WT \& VWF-DEL, n=3, red circles; both VWF-WT \& VWF-DEL/C2773R n=4, blue circles is shown. (E) Mice that were able to spontaneously arrest the bleeding in the tailclip assay have been referred as non-bleeders (white) and mice that never arrest the bleeding have been named bleeders (grey). The ratio of bleeders versus non-bleeders was similar in mice expressing mVWF-WT and mVWF-WT \& -DEL/C2773R as compared with mice expressing mVWF-WT \& -DEL.

Statistical significance was calculated by applying a one-way ANOVA with Tukey's multiple comparisons using Prism 7 (Graphpad) software, in panels $C$ and D. ( ${ }^{* *} P<0.01$; ${ }^{* *} P<0.001$ and $n s \mathrm{P}>0.05)$. Error bars in the graphs indicate standard deviation from the mean. 
Figure 1

Campioni $\mathrm{M}$ et al

Modulating dominant-negative variants in mouse models of VWD
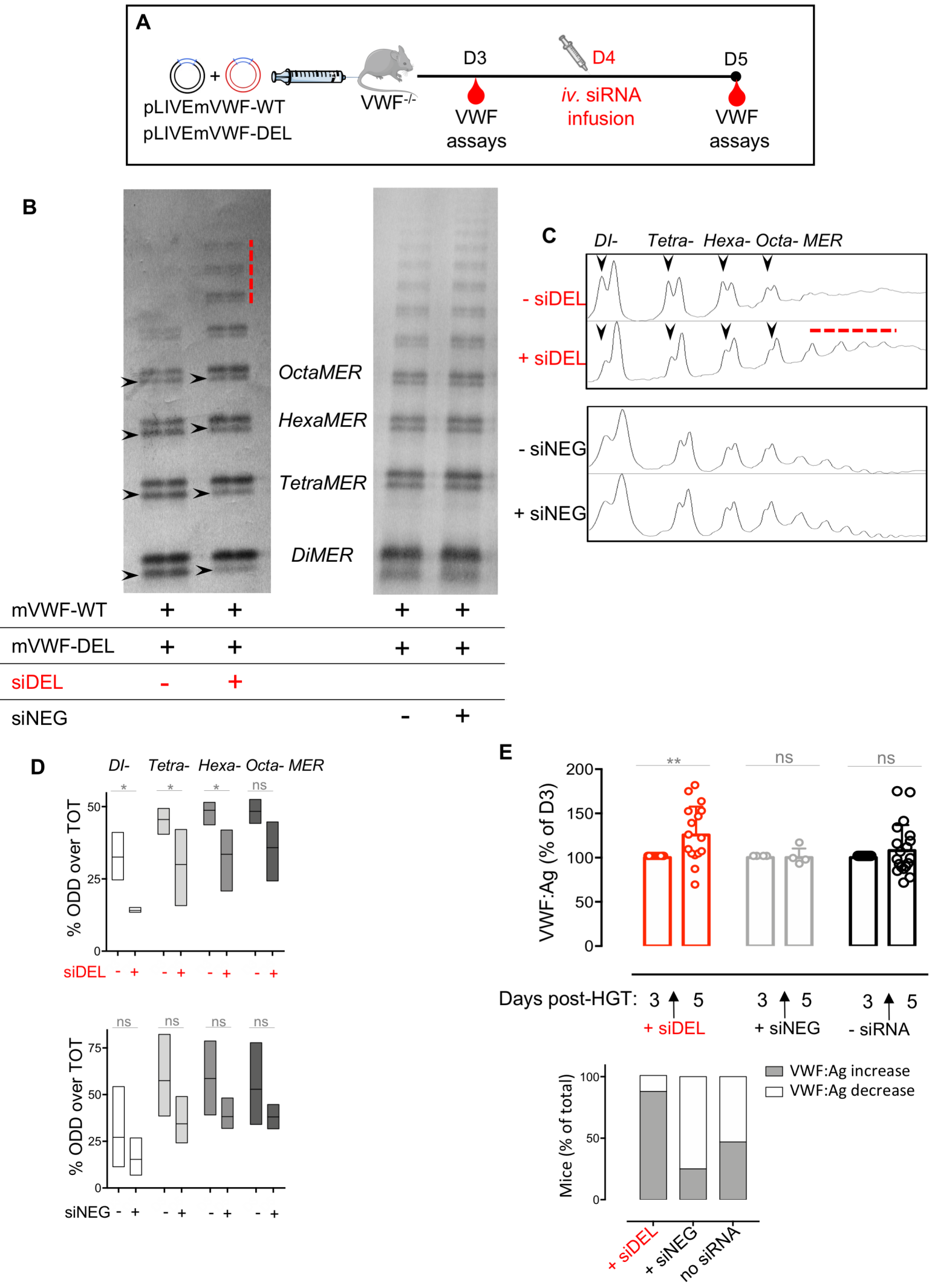
Figure 2

Campioni $\mathrm{M}$ et al

Modulating dominant-negative variants in mouse models of VWD



B

$3 \%$ agarose gel

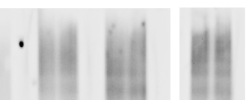

C

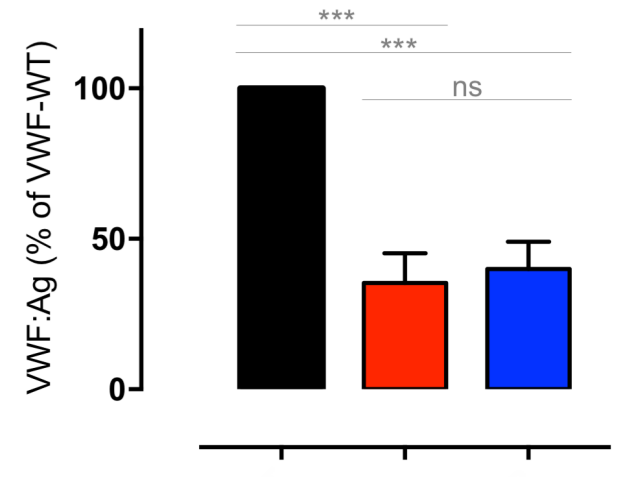

\begin{tabular}{lllll} 
VWF-WT & + & + & + & + \\
\hline VWF-DEL & + & & & \\
\hline VWF-DEL/C2773R & & & + & +
\end{tabular}

\begin{tabular}{llll} 
VWF-WT & + & + & + \\
\hline VWF-DEL & & + & \\
\hline VWF-DEL/C2773R & & &
\end{tabular}


Figure 3

Campioni $\mathrm{M}$ et al

Modulating dominant-negative variants in mouse models of VWD

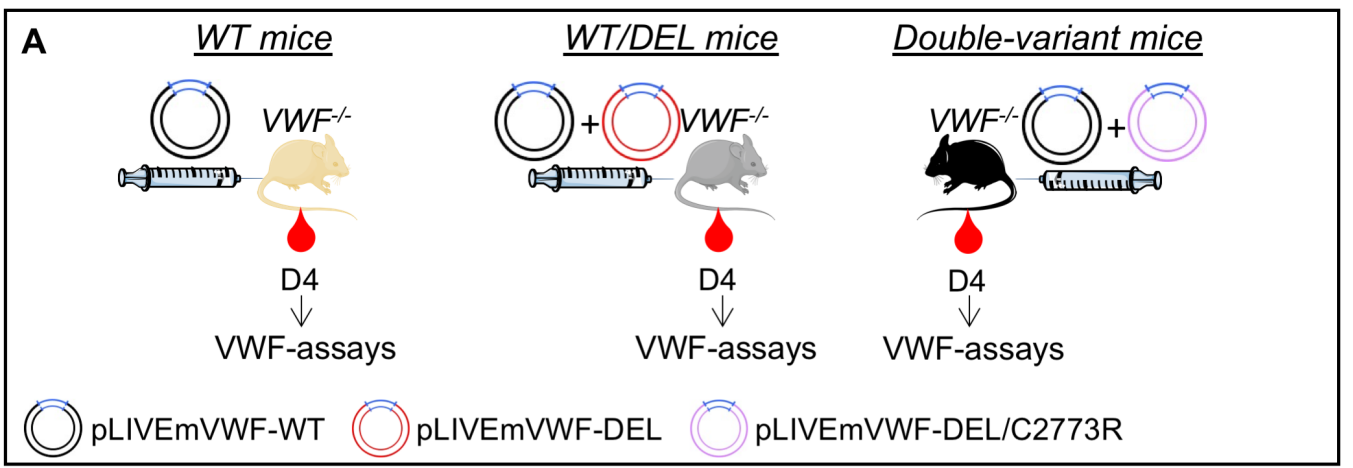

B



C

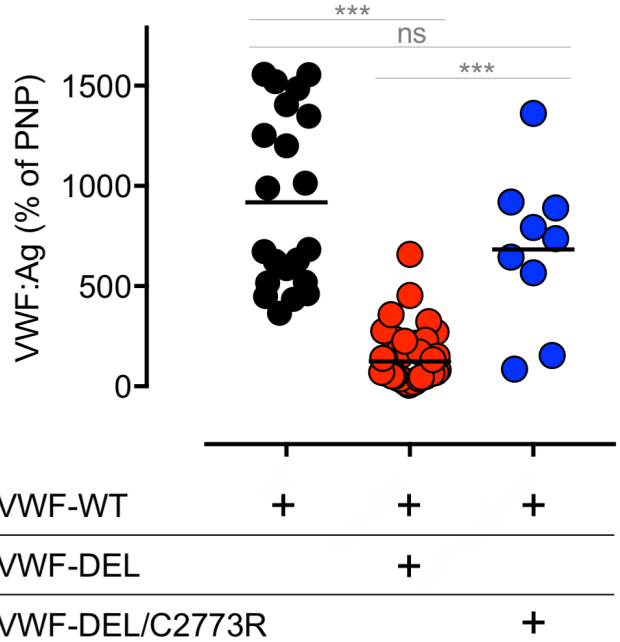

D

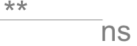

E
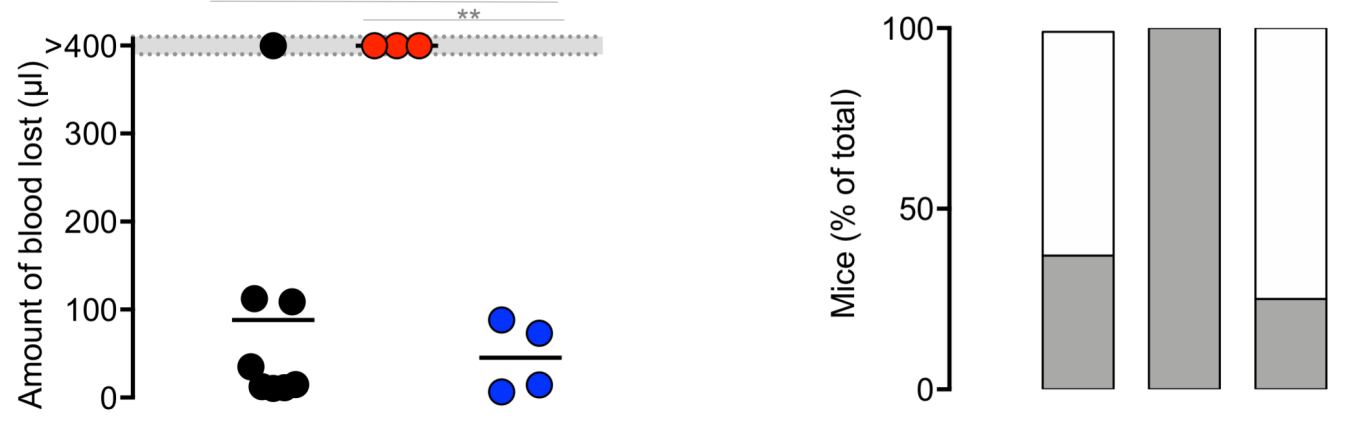

\begin{tabular}{llll} 
mVWF-WT & + & + & + \\
\hline mVWF-DEL & & + & \\
\hline mVWF-DEL/C2773R & & & +
\end{tabular}

\begin{tabular}{llll} 
mVWF-WT & + & + & + \\
\hline mVWF-DEL & & + & \\
\hline mVWF-DEL/C2773R & & & +
\end{tabular}

$\square$ non-bleeders $\square$ bleeders 